\title{
A Bibliometric Analysis of Childhood Malnutrition Research Productivity in Africa over a Twenty-Year Period (1999-2019)
}

\author{
Mukhtar A. Ijaiya1, Seun Anjorin'2, Olalekan A. Uthman' \\ ${ }^{1}$ Jhpiego, Abuja, Nigeria \\ ${ }^{2}$ Warwick Centre for Applied Health Research and Delivery (WCAHRD), Division of Health Sciences, Warwick Medical School, \\ University of Warwick, Coventry, UK \\ Email: Mukhtarijaiya@yahoo.com
}

How to cite this paper: Ijaiya, M.A., Anjorin, S. and Uthman, O.A. (2021) A Bibliometric Analysis of Childhood Malnutrition Research Productivity in Africa over a Twenty-Year Period (1999-2019). Journal of Biosciences and Medicines, 9, 40-54. https://doi.org/10.4236/jbm.2021.910004

Received: August 28, 2021

Accepted: October 11, 2021

Published: October 14, 2021

Copyright $\odot 2021$ by author(s) and Scientific Research Publishing Inc. This work is licensed under the Creative Commons Attribution International License (CC BY 4.0).

http://creativecommons.org/licenses/by/4.0/

\begin{abstract}
Background: Africa remains the epicenter of the global burden of malnutrition and the only region the number of stunted children is on the rise. A major cause of morbidity and mortality amongst children, it has been associated with factors such as poverty, food insecurity, maternal education and socio-economic inequalities. The role of research publication has been noted in providing an important connection between knowledge creation and translation of evidence to practice. Therefore, to determine the trend and the efforts put in place to eliminate malnutrition in the African region, bibliometric analysis was used to cumulatively present research productivity. The aim of this study was to assess childhood malnutrition research productivity in Africa, quantifying gaps, the most significant factors associated with the citations and future bibliometrics study path. Methods: A search of the PubMed database was conducted in December 2020 in order to obtain the childhood malnutrition research volume of each African country over a twenty-year period. The search was conducted and metadata of publications and articles gathered from the PubMed database using the PubMedR package. A comparative weighting for population and Gross Domestic Product (GDP) was done by calculating the ratio of the number of articles from each country to their respective populations and GDP. Poisson regression models were used to examine the publication productivity time trends over the twenty-year period. The association between research productivity, population size and GDP were examined using the Pearson correlation analysis. Results: A total of 11,758 articles on childhood malnutrition indexed on PubMed were returned and described in this study. Six countries-South Africa, Ethiopia, Egypt, Nigeria, Kenya and Malawi account for about half of total publica-
\end{abstract}


tions. However, when controlled for population and GDP, much smaller countries Cape Verde, Swaziland, Gambia were most productive. Africa's relative share of the world's total childhood malnutrition publication rose from $6.2 \%$ in 1999 to a record high of $12.3 \%$ in 2019. Across the top 10 most productive countries by volume of research publication, there was a statistically significant average annual percent change. There was a strong positive and statistically significant correlation between total publications on childhood malnutrition and countries' population $(\mathrm{r}=0.65, \mathrm{P}<0.01)$. We also observed a strong positive and statistically significant correlation between total publications on childhood malnutrition and countries' GDP $(\mathrm{r}=0.60, \mathrm{P}<0.01)$. Conclusion: Africa's percentage share of the world's childhood malnutrition research output has experienced a steady improvement. There remains an under-representation of the continent in research productivity. Populous countries with relatively higher GDP had the most indexed articles, and much smaller countries were more efficient in terms of research productivity relative to population size and GDP.

\section{Keywords}

Bibliometric Analysis, Malnutrition, Childhood

\section{Introduction}

All Malnutrition remains a major cause of death and disease amongst children globally. An estimated 52 million children less than 5 years suffer from malnutrition leading to a variety of morbidity conditions [1]. One in every ten children suffer from low weight and about $45 \%$ of child deaths are associated with malnutrition [2] [3]. Malnutrition includes severe hunger, undernutrition and obesity which can jeopardize the life of a child even until adult stage [4] [5]. Studies have shown that low birth weight and undernutrition were subsequently risk factors for high glucose concentrations and increased blood pressure rate observed at an adult stage [6].

Malnutrition arises as a result of insufficient or excess intake of nutrient or as a result of imbalanced intake of adequate diet in the body. Malnutrition encompasses undernutrition (stunting, underweight, wasting) or inadequate micronutrient deficiencies such as lack of vitamins and minerals as well as obesity and overweight [4]. This cuts across both developed and underdeveloped countries therefore, the need to combat malnutrition is a major priority globally such that, international policies and research are required to tackle the condition [1]. Although concerted efforts have been made through investments in malnutrition programs and research to reduce severe malnutrition especially in low- and middle-income countries, it is still very much prevalent. Global trends show that with the current level of efforts on tackling malnutrition, the world is not on course to meet the Sustainable Development Goal-2 (SDG) (Zero hunger) target for malnutrition [7]. 
Several literatures have documented the factors associated with childhood malnutrition which include poverty [7] [8], droughts [9], food insecurity, parental education, government policies, and socio-economic inequalities [10]. Additionally, other studies have found that factors such as household food insecurity, level of maternal education and no consumption of vitamin supplements contribute to malnutrition [11]. Overall, poverty has been found to be the most pervasive cause of childhood malnutrition [7] [11].

Child malnutrition is more prevalent in Africa and Asia than elsewhere globally [12]. However, Africa bears most of the burden of all malnutrition and it is the only region where the number of stunted children is on the rise [4]. More than one quarter of children less than 5 years live in Africa and high childhood mortality is often associated with regions with severe malnutrition, with underlying malnutrition playing a main role in the risk of death [13]. Although other developed regions like North America suffer from overweight, the number of overweight children less than 5 years is gradually on the increase in Africa since the year 2000, thereby presenting "double burden of malnutrition" in the region [4] [14].

The role of research publication is important in providing an important connection between knowledge creation, approval and utilization [15] [16]. Publications and their citations (bibliometric) are the most appropriate method for quantitatively assessing scientific researches at several levels (global, institutional and individual) and have been utilized by different researchers [17] [18] [19] [20]. In order to determine the trend and the efforts put in place to eliminate malnutrition in the African region by different studies and reviews, bibliometric analysis will be utilized to cumulatively present research productivity of previous studies and reviews in Africa from 1999-2019. Of importance in 1999 was the launch of the public availability of the WHO Global Database on Child Growth and Malnutrition which provides a compilation of standardized and comparable nutritional survey results from around the world [21]. This will provide insight regarding the history and growth of childhood malnutrition research in Africa.

Therefore, the aim of the study is to assess childhood malnutrition research productivity in Africa, quantifying gaps, the most significant factors associated with the citations and future bibliometrics study path.

\section{Methods}

\subsection{Data Sources}

A search of the PubMed database was conducted in December 2020 in order to obtain the childhood malnutrition research volume of each African country over a twenty-year period from 1st January 1999 till 31st December 2019. The search was conducted using the $\mathrm{R}$ package and articles generated by specifying the search parameters: search terms, place and year of publication. The search terms used include "stunting [MeSH] OR stunting OR underweight [MeSH] OR underweight OR undernutrition $[\mathrm{MeSH}] \mathrm{OR}$ undernutrition". The names of the 
countries were imputed in their different possible forms, for example, "Cape Verde" = "Cape Verde OR Cabo Verde". Some names of countries are also names of parts of other countries, for example, Benin and Niger are names of African Countries and names of places in Nigeria. To eliminate this error, requisite search command restrictions were written: "Benin" = "Benin NOT Nigeria" and "Niger" = "Niger NOT Nigeria".

The study used childhood malnutrition research articles indexed in the PubMed database over the twenty-year period as proxy for total research productivity in Africa. The total number of publications was the total number of articles returned from the search indexed on PubMED for the twenty-year period. A comparative weighting for population and Gross Domestic Product (GDP) was done by calculating the ratio of the number of articles from each country to their respective populations and GDP. The population and GDP estimates were obtained from the World Development Indicators database of the world bank [22]. Thereafter, three top 10 lists of countries with the highest absolute number of publications, the highest number of publications relative to population and GDP respectively were created.

\subsection{Statistical Analyses}

Poisson regression models were used to examine the publication productivity time trends over the twenty-year period, with the absolute number of publications as the outcome variable and the year of publication as the predictor variable. This further confers the ability to calculate average annual percentage changes across individual years of the twenty-year study period. The Poisson regression fits the model as detailed below:

$$
\ln (p)=a+\beta *(t)
$$

From the foregoing, $p$ equals number of articles per year, log is the natural $\log , a$ is the intercept, $\beta$ is the trend, and $t$ is the year-year starting from 1999. Average annual percentage changes (AAPC) were calculated using the following formula: $\mathrm{AAPC}=100 *(\exp (\beta)-1)$. The absolute and relative increases in the number of publications on the subject matter between the beginning and end of the search time period was also calculated:

Percent relative growth

$$
=\frac{\text { number of publications in } 2019}{\text { number of publications in } 2019-\text { number of publications in } 1999} \times 100
$$

Further analysis of the change in trend per year was conducted by assessing change over four 5-year periods (1999-2003, 2004-2008, 2009-2013 and 2014-2019). In addition, the proportion of Africa's research productivity in childhood malnutrition as a share of world research output was calculated for each year as below:

$$
\begin{aligned}
& \text { Annual Percent share of world's research ouptut } \\
& =\frac{\text { number of articles from Africa }}{\text { total number of articles indexed in PubMed }} \times 100
\end{aligned}
$$


Thereafter, the association between research productivity and population size was examined; and research productivity and GDP using the Pearson correlation analysis method. For correlation analysis, the number of publications, population size, and GDP were log transformed to linearise these associations. Data were processed and analyzed with $\mathrm{R}$, a free software environment for statistical computing and graphics. The search was conducted, and metadata of publications and articles gathered from the PubMed database using the PubMedR package.

\section{Results}

A total of 11,758 articles on childhood malnutrition indexed on PubMed were returned using the search parameters and described in this study. The last year (2019) of the twenty-year period had the highest research productivity with 1480 indexed articles, while 2001 was the year with the lowest research productivity with 174 indexed articles. Over the twenty-year period, South Africa had the greatest number of indexed articles (1876) accounting for $16 \%$ of the total indexed articles, and Sao Tome and Principe with the least number of indexed articles.

Africa's relative share of the world's total childhood malnutrition publication rose from $6.2 \%$ in 1999 to a record high of $12.3 \%$ in 2019, with Africa's lowest world share proportions in 2001 (4.2\%), 2006 (4.3\%), 2004 (4.4\%) and 2002 (4.6\%) (Figure 1). Moreover, since 2009 Africa's share of the world's research productivity in childhood malnutrition has not gone below $5.6 \%$.

Table 1 below shows the ten top ranking countries with the most indexed articles from the results of the search. These 10 countries account for over $60 \%$ of the articles described in this study. Over the study period, all countries except Guinea had a higher number of articles in 2019 compared to 1999. Similarly, Guinea, Nigeria, South Africa and United Republic of Tanzania's relative share

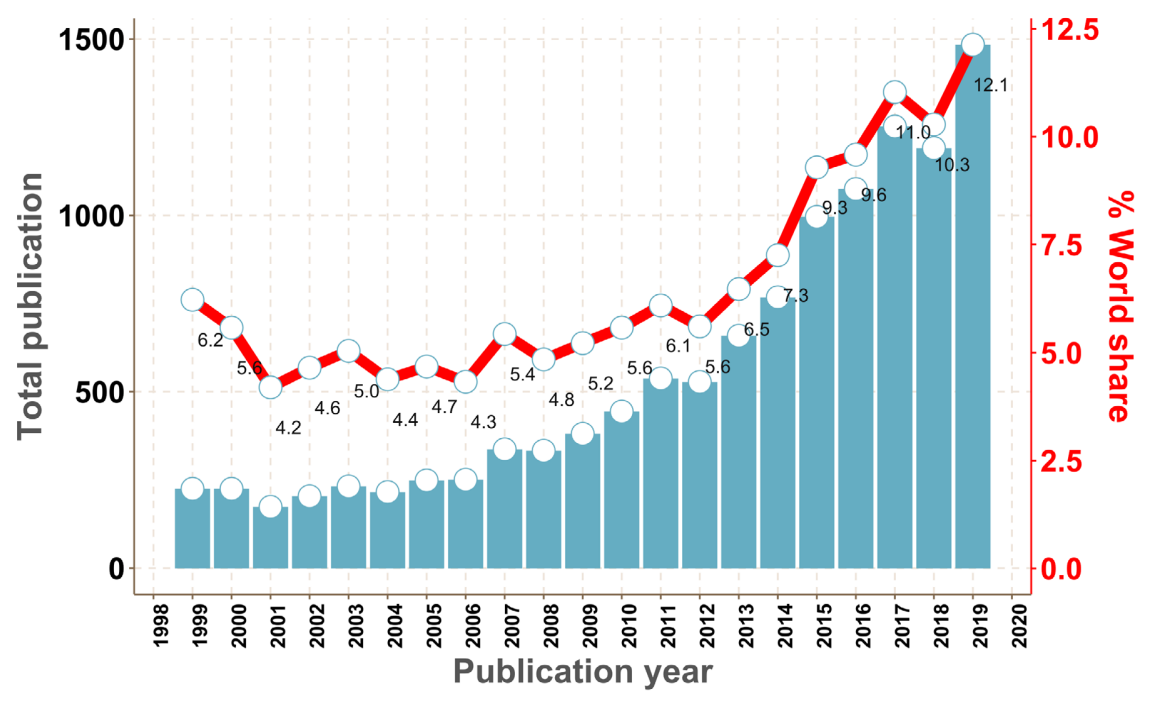

Figure 1. Africa's annual percent share of world's research output. 
Table 1. Number of articles indexed by PubMed from top 10 countries, percentage of Africa publication, relative growth, and Poisson regression analysis of annual percent change: 1999-2019.

\begin{tabular}{cccccccc}
\hline Country & $1999-2019$ & 1999 & 2019 & Absolute growth (\%) & Relative growth (\%) & AAPC & p-value \\
\hline Guinea & $379(3.2)$ & $19(8.4)$ & $16(1.1)$ & 84.2 & -15.8 & 1.9 & 0.031 \\
Uganda & $419(3.6)$ & $3(1.3)$ & $52(3.5)$ & 1733.3 & 1633.3 & 17.0 & $<0.001$ \\
United Republic of Tanzania & $429(3.6)$ & $11(4.9)$ & $57(3.9)$ & 518.2 & 418.2 & 13.3 & $<0.001$ \\
Swaziland & $516(4.4)$ & $7(3.1)$ & $87(5.9)$ & 1242.9 & 1142.9 & 15.4 & $<0.001$ \\
Malawi & $541(4.6)$ & $3(1.3)$ & $65(4.4)$ & 2166.7 & 2066.7 & 13.2 & $<0.001$ \\
Kenya & $722(6.1)$ & $5(2.2)$ & $103(7.0)$ & 2060 & 1960 & 14.3 & $<0.001$ \\
Nigeria & $789(6.7)$ & $19(8.4)$ & $86(5.8)$ & 452.6 & 352.6 & 8.9 & $<0.001$ \\
Egypt & $804(6.8)$ & $9(4.0)$ & $109(7.4)$ & 1211.1 & 1111.1 & 16.0 & $<0.001$ \\
Ethiopia & $910(7.7)$ & $16(7.1)$ & $178(12.0)$ & 1112.5 & 1012.5 & 19.1 & $<0.001$ \\
South Africa & $1876(16.0)$ & $38(16.9)$ & $233(15.7)$ & 613.2 & 513.2 & 11.5 & $<0.001$ \\
\hline
\end{tabular}

of indexed articles on childhood malnutrition in Africa decreased in 2019 compared to their relative share in 1999.

When analyzed across five-year bands (Figure 2) for the top 5 ranked countries in malnutrition research, South Africa ranked $1^{\text {st }}$ in childhood malnutrition research in all the bands: 1999-2003, 2004-2008, 2009-2013 and 2014-2019. Nigeria ranked second from 1999 till 2013 and dropped to $5^{\text {th }}$ in research productivity between 2014-2019. Guinea which was ranked $3^{\text {rd }}$ in research productivity between 1999-2003 and dropped to $7^{\text {th }}, 10^{\text {th }}$ and $14^{\text {th }}$ between 2003-2008, 2009-2013 and 2014-2019 respectively. Ethiopia's relative rank in malnutrition research productivity fluctuated from $4^{\text {th }}$ between 1999-2003, to $6^{\text {th }}$ between 2004-2008, to $5^{\text {th }}$ between 2009-2013 and improved to $2^{\text {nd }}$ between 2014-2019. Most significant was the change in Egypt's malnutrition research productivity ranking from $5^{\text {th }}$ between 1999-2003, to $4^{\text {th }}$ between 2004-2008 and $3^{\text {rd }}$ between 2009-2013 and 2014-2019.

Among the bottom 5 ranked countries in malnutrition research productivity between 1999-2003, Sao Tome and Principe ranked last $\left(57^{\text {th }}\right)$, moved to the second to the last $\left(56^{\text {th }}\right)$, back to $57^{\text {th }}$ and then up to $53^{\text {rd }}$ between $2003-2008$, 2009-2013 and 2014-2019 respectively. Equatorial Guinea which ranked 56 ${ }^{\text {th }}$ between 1999-2003 moved significantly up the ranking to the $44^{\text {th }}$ position between 2004-2008 and back to $56^{\text {th }}$ between 2009-2013 and finally ranked $55^{\text {th }}$ between 2014-2019. While Seychelles which ranked $55^{\text {th }}$ between 1999-2003 moved downwards to $57^{\text {th }}$ and upwards to $51^{\text {st }}$ initially and finally $46^{\text {th }}$ over five-year bands, Mauritania which ranked $54^{\text {th }}$ between 2009-2013 moved downwards to $55^{\text {th }}$, then upwards to $48^{\text {th }}$ rank and ended as the bottom ranked country between 2014-2019. While Gabon which was ranked 52 ${ }^{\text {nd }}$ between 1999-2003 had the most significant change moving to $39^{\text {th }}$ between $2004-2008,40^{\text {th }}$ between 2009-2013 and $45^{\text {th }}$ between 2014-2019.

Across the top 10 countries in Table 1, there was a continuous increase in 


\section{Relative Rank of Childhood Malnutrition Research in Africa, 1999 - 2019}

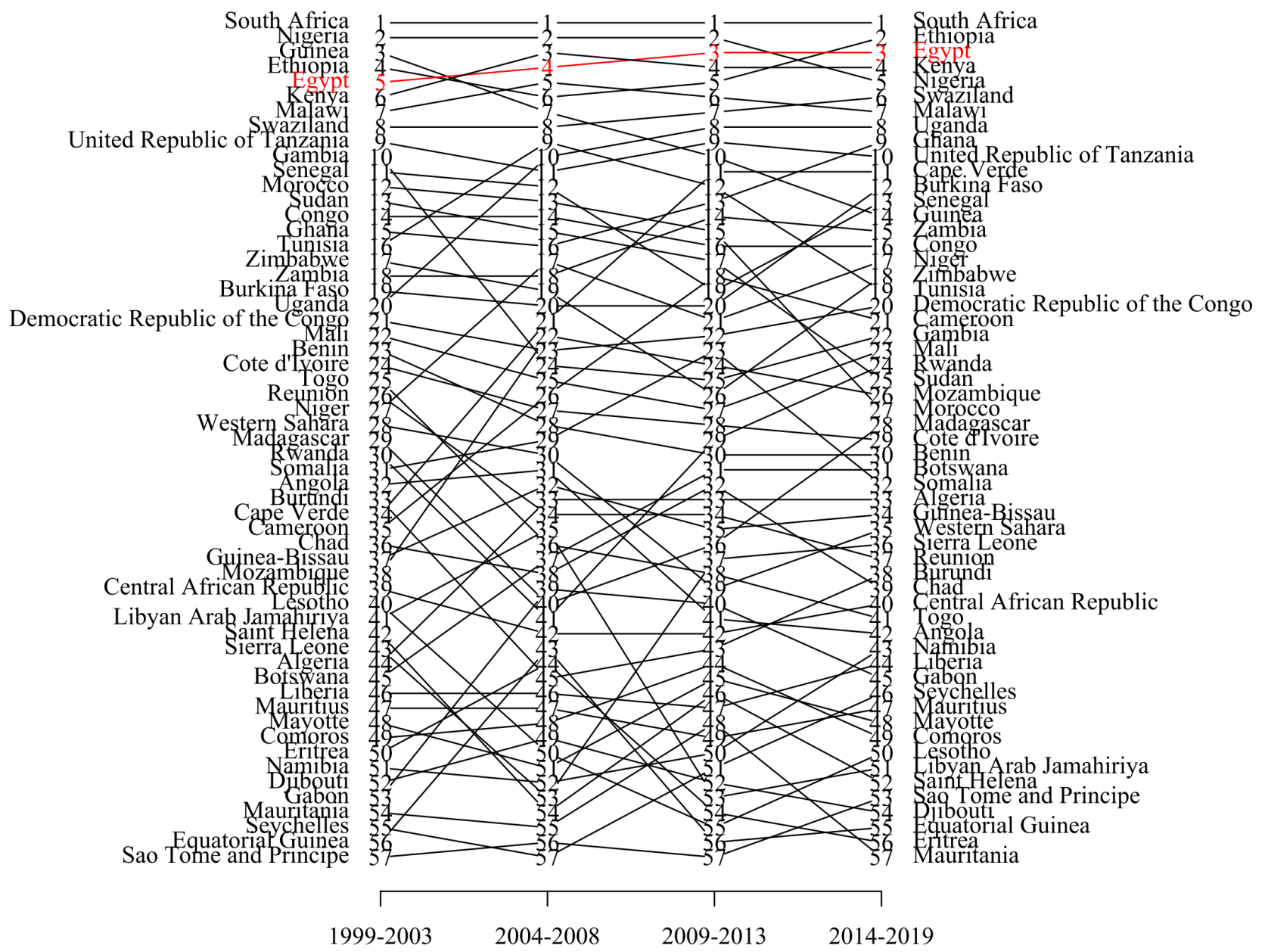

Figure 2. Relative rank of childhood malnutrition research in Africa, 1999-2019.

research productivity in the twenty-year study period. Ethiopia $(19.1 \%, \mathrm{P}<0.01)$ Uganda $(17.0 \%, \mathrm{P}<0.01)$ and Egypt $(16.0 \%, \mathrm{P}<0.01)$ had the most significant average annual percent change AAPC. Nigeria $(8.9 \%, \mathrm{P}<0.01)$ and Guinea $(1.9 \%, \mathrm{P}=0.031)$ had the least significant average annual percentage change and were the only two countries whose average annual percentage change were less than $10 \%$.

The map (Figure 3) below disaggregates research productivity over the twenty-year study period into quintiles. Seven countries that had between 501 to 2000 publications overall were in the highest quintile, followed by 21 countries with 101 to 500 publications in the second quintile, then 9 countries with 51 to 100 publications in the third quintile, 15 countries with 11 to 50 publications in the fourth quintile and 5 countries with 1 to 10 publications in the lowest quintile.

There was a strong positive and statistically significant correlation between total publications on childhood malnutrition and countries' population $(\mathrm{r}=$ 


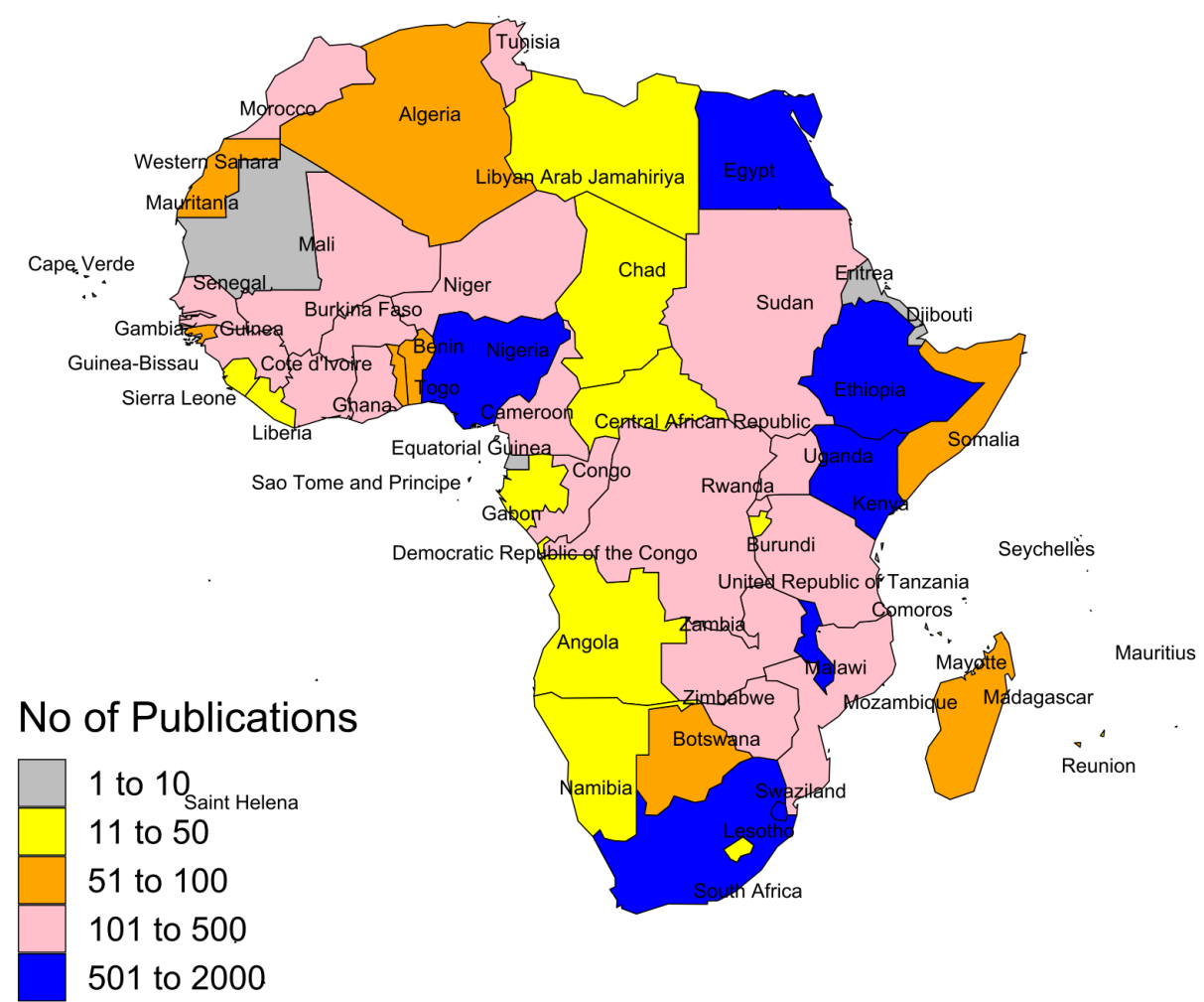

Figure 3. Colour-coded map representing total number of indexed PubMed Publications.

0.65, $\mathrm{P}<0.01$ ) as evidenced in Figure 4. Countries with large populations such as Nigeria, South Africa, Egypt, Ethiopia, and Kenya had the highest research productivity when compared with population on the logarithmic scale, and countries with much smaller populations like Sao Tome and Principe and Equatorial Guinea had the lowest research productivity when compared with population on the logarithmic scale.

We also observed a strong positive and statistically significant correlation between total publications on childhood malnutrition and countries' GDP ( $\mathrm{r}=$ $0.60, \mathrm{P}<0.01$ ) (Figure 5). Similarly, in Figure 5, same countries: Nigeria, South Africa, Egypt, Ethiopia, and Kenya; with large populations had the highest research productivity when compared with GDP on the logarithmic scale, and countries with much smaller populations like Sao Tome and Principe and Djibouti had the lowest research productivity when compared with GDP on the logarithmic scale. We also noted a strong positive and statistically significant correlation well as between countries' GDP and population $(\mathrm{r}=0.80, \mathrm{P}<0.01)$.

Although these countries: South Africa, Ethiopia, Nigeria, Kenya and Malawi; with large populations account for about $40 \%$ of all the publications, much smaller countries like Cape Verde, Swaziland, Gambia and Congo ranked $1^{\text {st }}, 2^{\text {nd }}$, $3^{\text {rd }}$ and $4^{\text {th }}$ are among the top 10 countries (Figure 6) when the publications are considered per million inhabitants, with Malawi (ranked $6^{\text {th }}$ ) and South Africa (ranked $7^{\text {th }}$ ) being the only exception. Guinea, Reunion, Botswana, and Seychelles (ranked $5^{\text {th }}, 8^{\text {th }}, 9^{\text {th }}$ and $10^{\text {th }}$ respectively) complete the ranking of top 10 


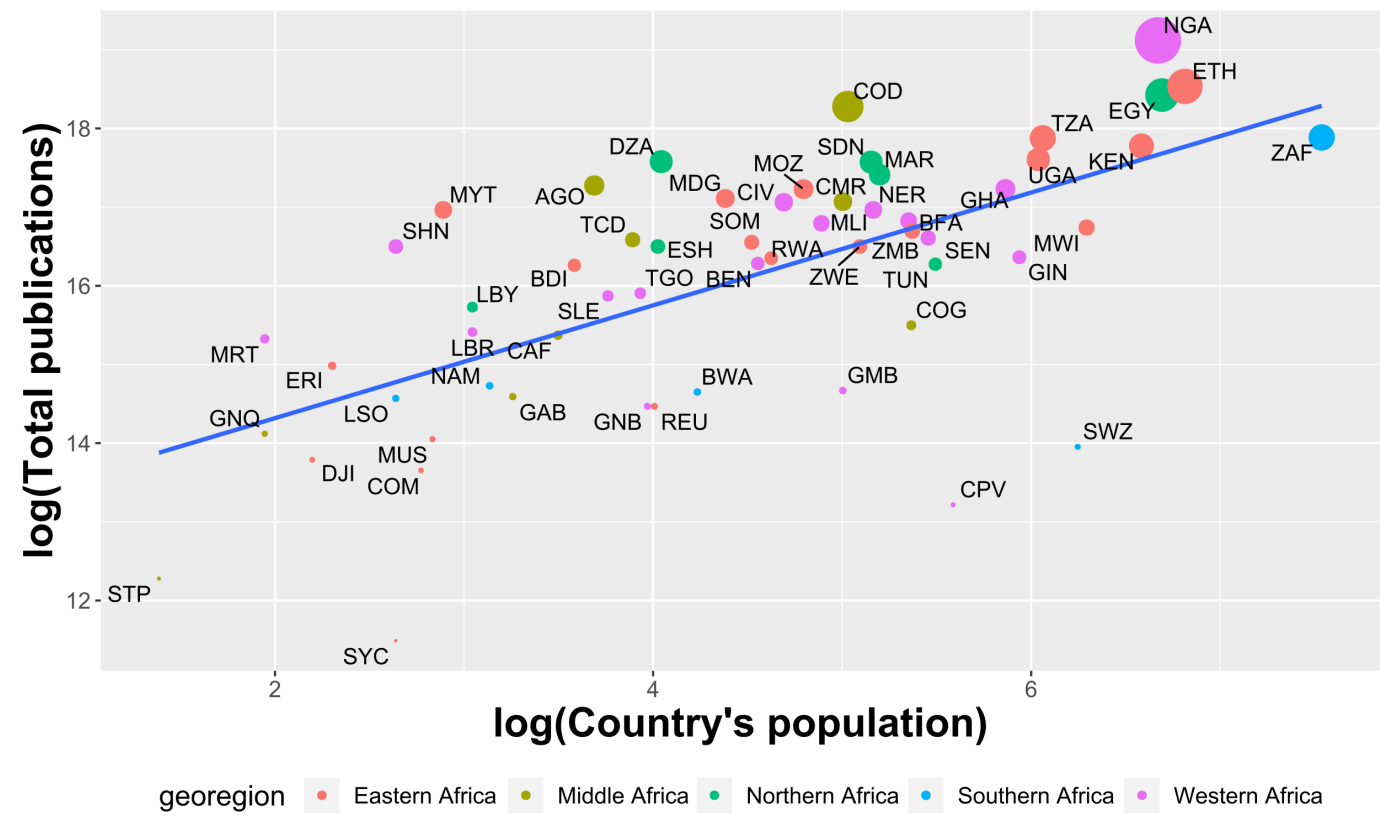

Figure 4. Scatter plot showing the association between total PubMed publications for different countries in Africa and the population of each country.

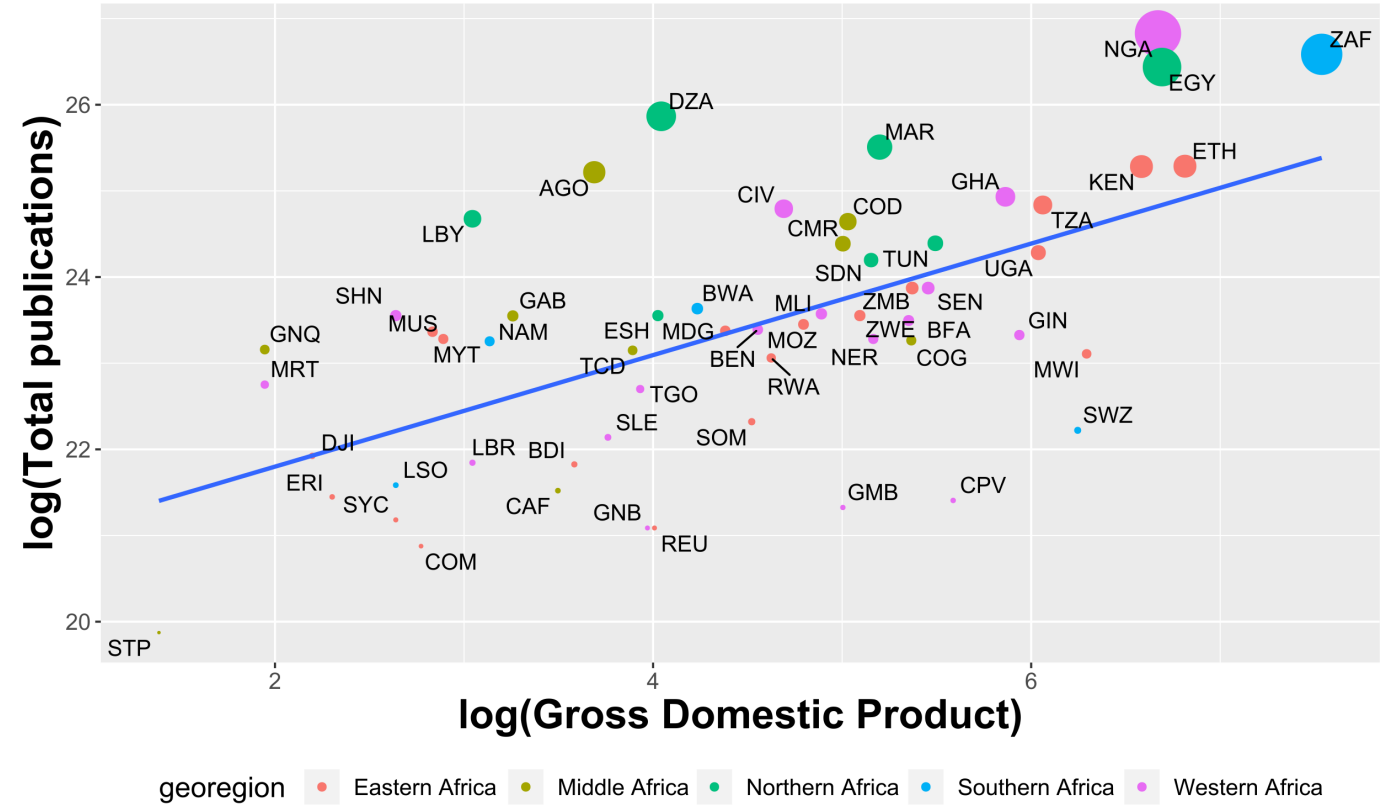

Figure 5. Scatter plot showing the association between total PubMed publications for different countries in Africa and the GDP of each country.

countries when the publications are considered per million inhabitants. Similarly, Gambia, Cape Verde and Swaziland ranked highest for total number of publications on childhood malnutrition relative to GDP (Figure 7). In addition, Malawi, Guinea, Reunion, and Congo also made the list of top 10 countries when total number of publications relative to GDP are ranked, with Guinea-Bissau, Somalia and Central Africa Republic completing the list. 


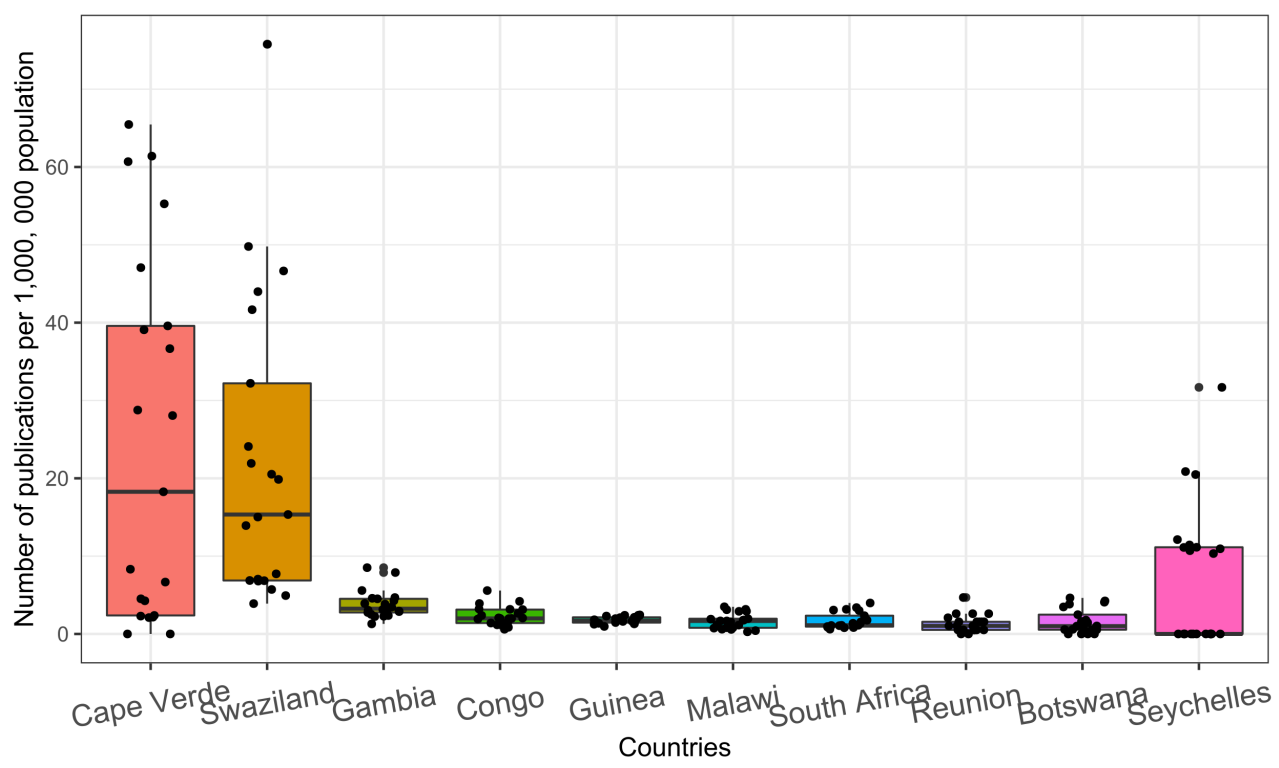

Figure 6. Top 10 countries and their number of PubMed publications per 1,000,000 populations per year during the period between 1999 and 2019.

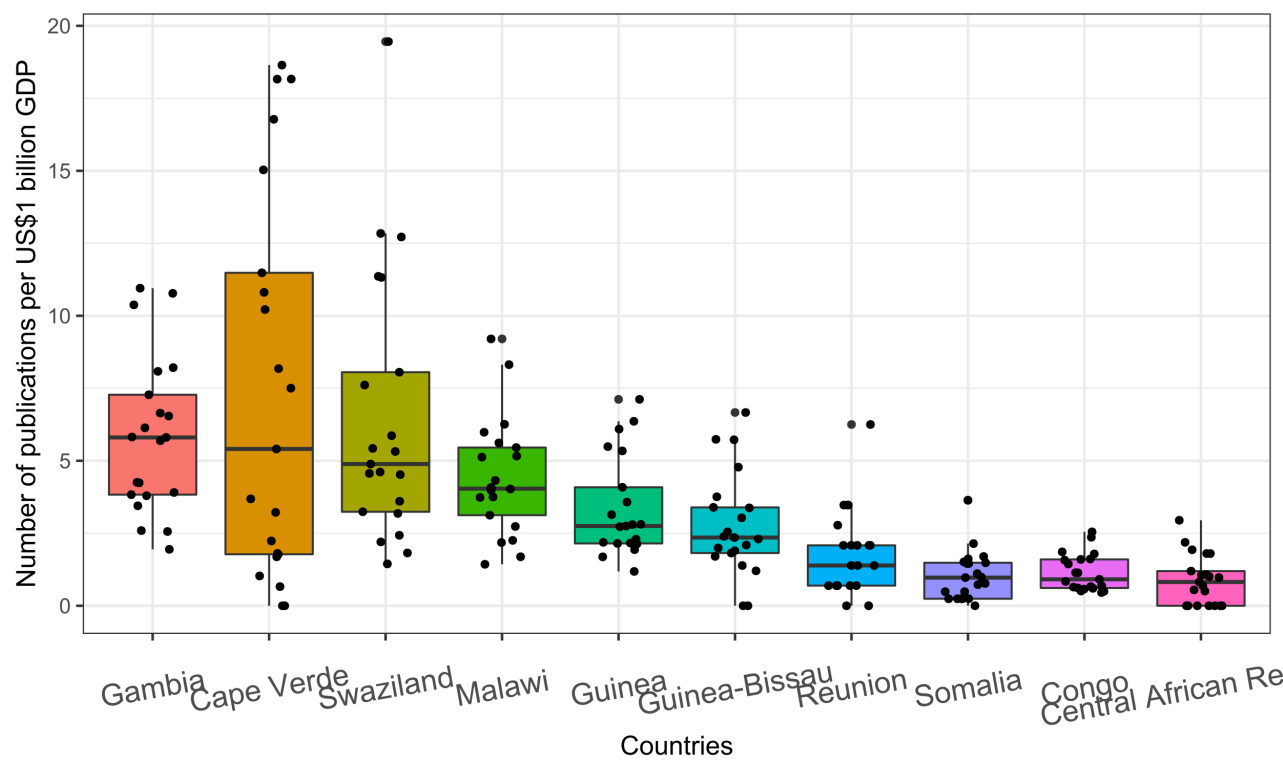

Figure 7. Top 10 countries and their number of PubMed publications per US\$1 billion GDP per year during the period between 1999 and 2019.

\section{Discussion}

This study presents the findings of a bibliometric analysis of articles on childhood malnutrition with the objective of describing Sub-Saharan Africa's research productivity over a twenty-year period. PubMed was used as the source of scientific information as it remains the optimal tool in biomedical electronic research [23]. While both Scopus, Web of Science and Google Scholar offer some advantages in journals breadth and citation analysis, PubMED remains the most used resource and offers advantages including its utilization of MESH vocabu- 
lary and specification of retrieval parameters as well as its ease of use [23] [24]. We found in this study that South Africa remains the country with the highest research productivity, similar to the findings in other studies [18] [20]. In addition, six countries-South Africa, Ethiopia, Egypt, Nigeria, Kenya and Malawi account for about half of total publications and together with an additional four countries (Swaziland, Tanzania, Uganda and Guinea) countries about $60 \%$ of total publications. This skewed distribution in research productivity on the African continent had been posited in earlier publications [20] [25].

Although Africa's share of malnutrition research productivity grew relatively steadily over the 20 -year periods and particularly in the last 10 years, there remains an under-representation of the continent in research productivity. It has been argued that authors from rich countries with investments in research and generation of new knowledge are at an advantage [26]. With only Seychelles classified as a high-income country on the continent [22], researchers on the continent face other challenges beyond funding such as infrastructural, human and technical capacity [25] [26] [27] [28] [29]. Moreover, studies [30] [31] [32] have documented the unbalanced composition of editorial and advisory boards in medicine in favor of academics from developed countries. Often over-looked is the donor agenda driven funding of research on the continent, which determines research specialization, partnerships and by extension publications [27] [29] [33]. Authors of African origin also have limited access to international journals and have been found to publish in local journals which are not usually available in electronically accessible medical libraries and journals [26] [27] [29]. This point has been further buttressed by [33], which concluded that electronic information sources and databases are not all encompassing of African biomedical publications.

On the continent, we noted that countries with bigger GDP had higher quantity of publications. In addition, same correlation exists between countries' population and research productivity. Besides the fact that there is also a positive and statistically significant relationship between GDP and population, the higher research productivity from these more populous African countries with relatively higher GDP (South Africa, Ethiopia, Egypt, Nigeria and Kenya) have been previously examined and has been attributed to higher numbers of tertiary and research institutions, journals and researchers across different specializations [20] [25] [34] [35] [36] [37]. Instructively, we also observed that relative to number of publications per million persons in a country, much smaller countries (Cape Verde, Swaziland and Gambia) were ranked highest and the most productive. Same countries but in a different order (Gambia, Cape Verde and Swaziland) were ranked highest and the most productive when total publications are compared relative to GDP.

Among the 10 countries with the most publications, Guinea, Nigeria, South Africa and Tanzania had a relative lower proportion of publications at the end of the study period compared to the beginning of the study period. When relative ranking overtime of these countries with a lower contribution to total publica- 
tions in 2019 are assessed, South Africa's position remained unchanged at 1st, while Nigeria, Guinea and Tanzania's relative ranks tanked from $2^{\text {nd }}$ to $5^{\text {th }}, 3^{\text {rd }}$ to $14^{\text {th }}$ and $9^{\text {th }}$ to $10^{\text {th }}$ respectively. They all however had a significant increase in average annual percentage change. Among these countries, only Guinea (francophone) and Egypt (Arabic-speaking) were not English-speaking countries, with English widely spoken in Ethiopia and a medium of instruction in schools although not an official language. The extent to which language played a role in research productivity cannot be determined, however some researchers [25] [26] [29] have argued that authors from non-English countries are at a publishing disadvantage with problems of presentation, writing style and language proficiency.

The search, aggregation and analysis conducted for this study were objective and comprehensive to the authors' best efforts. However, only relevant articles indexed on PubMED which served as the sole source of scientific information were included in the study. In addition, majority of the studies on PubMED are in English Language, thereby possibly biasing the study findings. As had been highlighted earlier, a number of research publications on the continent remain inaccessible through electronic databases. Authors' contribution attributions can also be misleading as their addresses on research articles are reflective of their respective institutions, organizations, affiliations or country of employment when they may not necessarily be resident/citizens of the same.

\section{Conclusion}

This study quantitatively assessed childhood malnutrition research productivity in Africa over a twenty-year period, with Africa's percentage share of the world's research output experiencing a steady improvement. Populous countries with relatively higher GDP had the most indexed articles, however a number of much smaller countries were more efficient in terms of research productivity relative to population size and GDP. Overall, while there were changes in relative rank of countries overtime and proportion of total publications between 1999 and 2019, there was a continuous increase in research productivity among the top 10 most productive countries who account for about $60 \%$ of the total number of publications. As had been highlighted, a key to combatting childhood malnutrition is addressing the social determinants of health: both a cause and consequence.

\section{Acknowledgements}

All authors participated in discussions about the data source and planning of the analyses, and critically revised successive versions of the paper. MAI and OAU conceived the study, MAI and SA did the analyses, and MAI prepared the first draft of the paper. All authors have seen and approved the final version of the paper.

\section{Conflicts of Interest}

The authors declare no conflicts of interest regarding the publication of this paper. 


\section{References}

[1] Webb, P., Stordalen, G.A., Singh, S., Wijesinha-Bettoni, R., Shetty, P. and Lartey, A. (2018) Hunger and Malnutrition in the 21st Century. British Medical Journal, 361, k2238. https://doi.org/10.1136/bmj.k2238

[2] WHO (2019) Malnutrition Is a World Health Crisis. https://www.who.int/news/item/26-09-2019-malnutrition-is-a-world-health-crisis

[3] UNICEF (2020) Malnutrition: A Major Cause of Death in Children. https://www.unicef.org/wca/malnutrition

[4] UNICEF, WHO and World Bank Group (2017) Levels and Trends in Child Malnutrition. United Nations Fund, World Health Organization and World Bank Group.

[5] Schaible, U.E. and Kaufmann, S.H. (2007) Malnutrition and Infection: Complex Mechanisms and Global Impacts. PLoS Medicine, 4, e115. https://doi.org/10.1371/journal.pmed.0040115

[6] Black, R.E., Victora, C.G., Walker, S.P., Bhutta, Z.A., Christian, P., De Onis, M., et al. (2013) Maternal and Child Undernutrition and Overweight in Low-Income and Middle-Income Countries. The Lancet, 382, 427-451. https://doi.org/10.1016/S0140-6736(13)60937-X

[7] UNICEF (2019) The State of the World's Children 2019-Children, Food and Nutrition: Growing Well in a Changing World.

[8] Tette, E.M., Sifah, E.K. and Nartey, E.T. (2015) Factors Affecting Malnutrition in Children and the Uptake of Interventions to Prevent the Condition. BMC Pediatrics, 15, Article No. 189. https://doi.org/10.1186/s12887-015-0496-3

[9] Belesova, K., Agabiirwe, C.N., Zou, M., Phalkey, R. and Wilkinson, P. (2019) Drought Exposure as a Risk Factor for Child Undernutrition in Low and Middle-Income Countries: A Systematic Review and Assessment of Empirical Evidence. Environment International, 131, Article No. 104973. https://doi.org/10.1016/j.envint.2019.104973

[10] Bain, L.E., Awah, P.K., Geraldine, N., Kindong, N.P., Sigal, Y., Bernard, N., et al. (2013) Malnutrition in Sub-Saharan Africa: Burden, Causes and Prospects. The Pan African Medical Journal, 15, Article No. 120. https://doi.org/10.11604/pamj.2013.15.120.2535

[11] Poda, G.G., Hsu, C.Y. and Chao, J.C. (2017) Factors Associated with Malnutrition among Children $<5$ Years Old in Burkina Faso: Evidence from the Demographic and Health Surveys IV 2010. International Journal for Quality in Health Care, 29, 901-908. https://doi.org/10.1093/intqhc/mzx129

[12] Victora, C.G., Adair, L., Fall, C., Hallal, P.C., Martorell, R., Richter, L., et al. (2008) Maternal and Child Undernutrition: Consequences for Adult Health and Human Capital. The Lancet, 371, 340-357. https://doi.org/10.1016/S0140-6736(07)61692-4

[13] Bhutta, Z.A., Berkley, J.A., Bandsma, R.H.J., Kerac, M., Trehan, I. and Briend, A. (2017) Severe Childhood Malnutrition. Nature Reviews Disease Primers, 3, Article No. 17067. https://doi.org/10.1038/nrdp.2017.67

[14] WHO (2017) The Double Burden of Malnutrition.

[15] Lewin, S., Lavis, J.N., Oxman, A.D., Bastías, G., Chopra, M., Ciapponi, A., et al. (2008) Supporting the Delivery of Cost-Effective Interventions in Primary Health-Care Systems in Low-Income and Middle-Income Countries: An Overview of Systematic Reviews. The Lancet, 372, 928-939. https://doi.org/10.1016/S0140-6736(08)61403-8

[16] Wiysonge, C.S. and Volmink, J. (2002) Strengthening Research Capacity. The Lancet, 359, 713. https://doi.org/10.1016/S0140-6736(02)07798-X 
[17] Musa, T.H., Akintunde, T.Y., Musa, H.H., Ghimire, U. and Gatasi, G. (2021) Malnutrition Research Output: A Bibliometric Analysis for Articles Index in Web of Science between 1900 and 2020. Electronic Journal of General Medicine, 18, Article No. em293. https://doi.org/10.29333/ejgm/10840

[18] Sweileh, W.M., Al-Jabi, S.W., Sawalha, A.F., AbuTaha, A.S. and Zyoud, S.H. (2016) Bibliometric Analysis of Medicine-Related Publications on Poverty (2005-2015). Springerplus, 5, Article No. 1888. https://doi.org/10.1186/s40064-016-3593-3

[19] Iftikhar, P.M., Ali, F., Faisaluddin, M., Khayyat, A., De Gouvia De Sa, M. and Rao, T. (2019) A Bibliometric Analysis of the Top 30 Most-Cited Articles in Gestational Diabetes Mellitus Literature (1946-2019). Cureus, 11, e4131. https://doi.org/10.7759/cureus.4131

[20] Wiysonge, C.S., Uthman, O.A., Ndumbe, P.M. and Hussey, G.D. (2013) A Bibliometric Analysis of Childhood Immunization Research Productivity in Africa since the Onset of the Expanded Program on Immunization in 1974. BMC Medicine, 11, Article No. 66. https://doi.org/10.1186/1741-7015-11-66

[21] De Onis, M. and Blössner, M. (2003) The World Health Organization Global Database on Child Growth and Malnutrition: Methodology and Applications. International Journal of Epidemiology, 32, 518-526. https://doi.org/10.1093/ije/dyg099

[22] Data Bank (2020) World Development Indicators. https://databank.worldbank.org/source/world-development-indicators

[23] Shultz, M. (2007) Comparing Test Searches in PubMed and Google Scholar. Journal of the Medical Library Association, 95, 442-445. https://doi.org/10.3163/1536-5050.95.4.442

[24] Falagas, M.E., Pitsouni, E.I., Malietzis, G.A. and Pappas, G. (2008) Comparison of PubMed, Scopus, Web of Science, and Google Scholar: Strengths and Weaknesses. The FASEB Journal, 22, 338-342. https://doi.org/10.1096/fj.07-9492LSF

[25] Uthman, O.A. and Uthman, M.B. (2007) Geography of Africa Biomedical Publications: An Analysis of 1996-2005 PubMed Papers. International Journal of Health Geographics, 6, Article No. 46. https://doi.org/10.1186/1476-072X-6-46

[26] Sumathipala, A., Siribaddana, S. and Patel, V. (2004) Under-Representation of Developing Countries in the Research Literature: Ethical Issues Arising from a Survey of Five Leading Medical Journals. BMC Medical Ethics, 5, Article No. 5. https://doi.org/10.1186/1472-6939-5-5

[27] Chaabna, K., Cheema, S., Abraham, A., Maisonneuve, P., Lowenfels, A.B. and Mamtani, R. (2021) The State of Population Health Research Performance in the Middle East and North Africa: A Meta-Research Study. Systematic Reviews, 10, Article No. 1. https://doi.org/10.1186/s13643-020-01552-x

[28] De Graft Aikins, A., Arhinful, D.K., Pitchforth, E., Ogedegbe, G., Allotey, P. and Agyemang, C. (2012) Establishing and Sustaining Research Partnerships in Africa: A Case Study of the UK-Africa Academic Partnership on Chronic Disease. Globalization and Health, 8, Article No. 29. https://doi.org/10.1186/1744-8603-8-29

[29] Van der Veken, K., Belaid, L., Delvaux, T. and De Brouwere, V. (2017) Research Capacity Building through North-South-South Networking: Towards True Partnership? An Exploratory Study of a Network for Scientific Support in the Field of Sexual and Reproductive Health. Health Research Policy and Systems, 15, Article No. 39. https://doi.org/10.1186/s12961-017-0202-z

[30] Horton, R. (2003) Medical Journals: Evidence of Bias against the Diseases of Poverty. The Lancet, 361, 712-713. https://doi.org/10.1016/S0140-6736(03)12665-7

[31] Tutarel, O. (2004) Composition of the Editorial Boards of Leading Medical Educa- 
tion Journals. BMC Medical Research Methodology, 4, Article No. 3.

https://doi.org/10.1186/1471-2288-4-3

[32] Xu, B., Meng, H., Qin, S., Liu, Y., Li, Z., Cao, J., et al. (2019) How International Are the Editorial Boards of Leading Spine Journals? A STROBE-Compliant Study. Medicine, 98, e14304. https://doi.org/10.1097/MD.0000000000014304

[33] Tijssen, R.J.W. (2007) Africa's Contribution to the Worldwide Research Literature: New Analytical Perspectives, Trends, and Performance Indicators. Scientometrics, 71, 303-327. https://doi.org/10.1007/s11192-007-1658-3

[34] Falagas, M.E., Papastamataki, P.A. and Bliziotis, I.A. (2006) A Bibliometric Analysis of Research Productivity in Parasitology by Different World Regions during a 9-Year Period (1995-2003). BMC Infectious Diseases, 6, Article No. 56. https://doi.org/10.1186/1471-2334-6-56

[35] Keiser, J., Utzinger, J., Tanner, M. and Singer, B.H. (2004) Representation of Authors and Editors from Countries with Different Human Development Indexes in the Leading Literature on Tropical Medicine: Survey of Current Evidence. British Medical Journal, 328, 1229-1232. https://doi.org/10.1136/bmj.38069.518137.F6

[36] Michalopoulos, A. and Falagas, M.E. (2005) A Bibliometric Analysis of Global Research Production in Respiratory Medicine. Chest, 128, 3993-3998.

https://doi.org/10.1378/chest.128.6.3993

[37] Soteriades, E.S., Rosmarakis, E.S., Paraschakis, K. and Falagas, M.E. (2006) Research Contribution of Different World Regions in the Top 50 Biomedical Journals (1995-2002). The FASEB Journal, 20, 29-34. https://doi.org/10.1096/fj.05-4711lsf 